\title{
LA IMPROCEDENCIA DEL AMPARO DIRECTO POR CESACIÓN DE EFECTOS DEL ACTO RECLAMADO
}

Carlos Alberto LÓPEZ DEL RÍo

\section{INTRODUCCIÓN}

Como es sabido, en nuestro país el juicio de amparo es el medio de control constitucional por antonomasia. Fue creado a favor de los gobernados para la defensa de sus derechos subjetivos públicos $\mathrm{y}$, específicamente, para lograr la restitución en el goce de las garantías individuales que han sido violadas por algún acto de autoridad. Este elevado objetivo obliga a considerar que dicho juicio debe ser eficaz y su trámite lo más ágil y sencillo que sea posible, pues de otro modo la defensa de los derechos del gobernado se haría nugatoria o, por lo menos, ardua y tortuosa.

Este trabajo está en concordancia con la idea de reducir u obviar trámites y evitar juicios innecesarios, porque en él se examina un problema referente a la forma como deben ser resueltos los amparos directos relacionados, con base en el estudio de una tesis jurisprudencial emitida por la Segunda Sala de la Suprema Corte de Justicia de la Nación.

En tal sentido, aunque el título de este breve artículo podría llevar a inducir la idea de que se analizarán todos los supuestos en los que, tratándose del amparo directo, puede actualizarse la causal de improcedencia prevista en el artículo 73, fracción XVI, de la Ley Reglamentaria de los Artículos 103 y 107 Constitucionales, en realidad, como se precisó, sólo se examinará un aspecto específico de esa cuestión, concretamente al que se refirió la mencionada Segunda Sala, al emitir la tesis de jurisprudencia número 225/2007, cuyo texto dice: 
JUICIO DE GARANTÍAS RELACIONADO, DEJÓ INSUBSISTENTE EL LAUDO RECLAMADO. Si un Tribunal Colegiado de Circuito conoce simultáneamente de dos juicios de amparo en materia laboral, en los que se combate el mismo acto reclamado, pero en uno de ellos determina conceder la protección constitucional para el efecto de que la autoridad responsable deje insubsistente el laudo reclamado y reponga el procedimiento, es inconcuso que cuando resuelva el otro amparo relacionado debe sobreseer en el juicio en términos del artículo 74, fracción III, en concordancia con el numeral 73, fracción XVI, ambos de la Ley de Amparo, pues en tal evento el laudo ya no produce efectos ni causa agravio alguno al quejoso, y de esta suerte, es innecesario que se ocupe del estudio de los conceptos de violación sea cual fuere su naturaleza, esto es, sin que trascienda si están referidos al fondo de la cuestión debatida o en ellos se aduzcan violaciones procesales. ${ }^{1}$

Dicho criterio derivó de la contradicción de tesis número 128/2007, entre las sustentadas por el Segundo Tribunal Colegiado del Décimo Primer Circuito y el Segundo Tribunal Colegiado en Materia de Trabajo del Cuarto Circuito, que fue resuelta por mayoría de tres votos en sesión del 31 de octubre de 2007, con el voto en contra de la ministra Margarita Beatriz Luna Ramos — quien desafortunadamente no formuló voto particular-, y con la ausencia del ministro Genaro David Góngora Pimentel.

El criterio aprobado por la Segunda Sala, que es de observancia obligatoria para los diversos órganos jurisdiccionales precisados en el artículo 192 de la Ley de Amparo, fue en el sentido de que cuando se tramitan dos juicios de amparo directo que se relacionan en términos del artículo 65 de la ley de la materia, y en uno de ellos se concede la protección constitucional para el efecto de que se reponga el procedimiento por la existencia de alguna violación de carácter procesal que trascendió al resultado del fallo, entonces el otro juicio debe ser sobreseído, independientemente de que en él se también se alegue la existencia de violaciones procesales o no y de que éstas pudieran ser anteriores o posteriores a la que motivó la concesión en el primer amparo relacionado o la importancia que dicha violación pueda tener en el procedimiento de origen.

No obstante, estimo que existen algunas razones de carácter jurídico y de economía procesal que podrían haber justificado una solución distinta o, por lo menos, un criterio diferenciado que considerara las peculiarida-

1 Semanario Judicial de la Federación y su Gaceta, Novena Época, t. XXVI, diciembre de 2007, p. 151. 
des de cada asunto, y para tratar de respaldar esta afirmación, en seguida sintetizaré las razones en las que se apoyaron los tribunales colegiados que participaron en la contradicción, y luego las consideraciones que expresó la mayoría de ministros de la Segunda Sala para emitir el criterio contenido en la tesis que aquí se comenta, para finalmente expresar los motivos por los que, a mi juicio, el asunto pudo haber sido resuelto en un sentido diverso.

Ahora bien, antes de iniciar considero pertinente precisar que es cierto que la jurisprudencia de la Corte es de observancia obligatoria para los órganos jurisdiccionales indicados en el artículo 192 de la Ley de Amparo, y que su aplicación, como argumento de autoridad, puede servir para fundar y motivar el sentido de las resoluciones que emiten dichos órganos; sin embargo, esto no significa que se trate de un ídolo inmaculado ni que sea una profanación analizar su contenido para emitir un comentario sobre su razonabilidad. Esto sólo sería entendible — no justificado - en un Estado autoritario que prohíbe a sus ciudadanos pensar y discutir los criterios de sus órganos jurisdiccionales.

La jurisprudencia existe y es obligatoria, pero no por ello debe ser intocable, tanto así que existe la posibilidad de modificarla; y si es saludable para un régimen democrático y constitucional que sus ciudadanos participen en la discusión de los asuntos públicos, también lo es que puedan discutir el contenido de los criterios que emiten sus órganos de control constitucional, por la trascendencia que tienen para la vida de los habitantes del país.

\section{CONSIDERACIONES DE LOS TRIBUNALES COLEGIADOS QUE INTERVINIERON EN LA CONTRADICCIÓN DE TESIS 128/2007}

El Segundo Tribunal Colegiado del Décimo Primer Circuito, estimó lo siguiente:

- Que la parte tercera perjudicada había promovido un juicio de amparo directo reclamando el mismo laudo, y se le había otorgado la protección constitucional para el efecto de que la autoridad responsable dejara insubsistente dicho acto y en su lugar se ordenara la reposición del procedimiento para mandar aclarar la demanda, lo cual se traducía en la cesación de efectos del acto reclamado en el 
juicio de garantías relacionado, en términos del artículo 73, fracción XVI, de la Ley de Amparo.

- Que la violación procesal que había motivado la concesión del amparo, no sólo era de mayor magnitud o trascendencia, sino incluso anterior a la referida en el juicio relacionado, por lo cual esta última no constituía un obstáculo para la actualización de la mencionada causal de improcedencia (la Segunda Sala determinó que esta consideración no fue fundamental para decretar el sobreseimiento en el juicio de amparo relacionado).

Por su parte, el Segundo Tribunal Colegiado en Materia de Trabajo del Cuarto Circuito, sostuvo lo siguiente en varios juicios de amparo que estaban relacionados con otros en los que se había otorgado el amparo y que se resolvieron en la misma sesión; concretamente, estimó lo siguiente:

- Luego de examinar los conceptos de violación relacionados con violaciones procesales, determinó que no era oportuno estudiar los conceptos de violación planteados en torno a cuestiones de fondo, porque se había otorgado la protección constitucional a la parte tercera perjudicada en el juicio de amparo relacionado (en el que tenía el carácter de quejosa, evidentemente), para el efecto de que la autoridad responsable dejara insubsistente el laudo reclamado y ordenara la reposición del procedimiento, por lo cual negó la protección constitucional solicitada.

El primer problema que salta a la vista al observar las consideraciones de ambos tribunales colegiados, es el relativo a si existía o no contradicción de criterios. En la ejecutoria que dio origen a la tesis jurisprudencial 225/2007, se consideró que sí, por cuanto ambos tribunales colegiados se pronunciaron sobre una cuestión jurídica esencialmente igual, consistente en establecer los efectos que debe tener en un amparo directo en materia laboral, el hecho de que en un asunto relacionado - en el que se combate el mismo acto-, se conceda la protección constitucional por violaciones de carácter procesal y se ordene dejar insubsistente el laudo reclamado y la consecuente reposición del procedimiento.

De igual manera, se dijo que ambos órganos jurisdiccionales habían adoptado posiciones discordantes, porque uno de ellos consideró que, ante la concesión del amparo para que se dejara sin efectos el laudo reclamado, 
debería decretarse el sobreseimiento en el juicio de garantías relacionado en términos del artículo 73, fracción XVI, de la Ley de Amparo, sin analizar los conceptos de violación referentes a violaciones procesales, porque ya en el primer amparo se había otorgado la protección constitucional respecto de una violación de mayor magnitud y anterior a las planteadas en el segundo juicio; mientras que el otro Tribunal Colegiado examinó y desestimó los conceptos de violación planteados en el segundo juicio que se referían a violaciones procesales, sin reparar en su trascendencia ni en el momento en que ocurrieron dentro del procedimiento, y estimó que ante la concesión del amparo decretada en el primer juicio, no era oportuno examinar los restantes conceptos de violación relacionados con el fondo del asunto y negó el amparo.

Esa conclusión de la Sala, en cuanto a la existencia de la contradicción de tesis, me parece correcta, porque efectivamente uno de los tribunales colegiados sostuvo un criterio que es opuesto al del otro, en cuanto a la posibilidad de examinar o no conceptos de violación planteados en un juicio de amparo que tiene relación con uno diverso en el que se otorgó previamente la protección constitucional para que se repusiera el procedimiento del juicio de origen y posteriormente se dictara una nueva resolución.

\section{RAZONES QUE SE EXPRESARON PARA RESOLVER LA CONTRADICCIÓN DE TESIS 128/2007}

Para resolver la contradicción de tesis en la forma que lo hizo y emitir la tesis de jurisprudencia 225/200, la Segunda Sala de la Suprema Corte de Justicia de la Nación, se basó en las siguientes consideraciones:

1. Que si bien no había un criterio jurisprudencial exactamente aplicable que resolviera el problema planteado, sí existían varias tesis jurisprudenciales relacionadas con el tema, entre ellas la número 54/2001 emitida por el Pleno de la Suprema Corte de Justicia de la Nación, de rubro "CESACIÓN DE EFECTOS EN MATERIAS DE AMPARO Y DE CONTROVERSIA CONSTITUCIONAL. SUS DIFERENCIAS", la tesis de jurisprudencia 9/98, emitida por la propia Segunda Sala, de rubro "Sobreseimiento. CESACIÓN DE LOS EFECTOS DEL ACTO

2 Ibidem, abril de 2001, t. XIII, p. 882. 
RECLAMADO", ${ }^{3}$ y la tesis jurisprudencial 59/99, emitida por la misma Sala, de rubro "CESACIÓN DE EFECTOS EN AMPARO. ESTA CAUSA DE IMPROCEDENCIA SE ACTUALIZA CUANDO TODOS LOS EFECTOS DEL ACTO RECLAMADO SON DESTRUIDOS EN FORMA TOTAL E INCONDICIONAL". 4

2. Que de dichas tesis se infería que la causal de improcedencia a que se refiere el artículo 73, fracción XVI, de la Ley de Amparo, se actualiza cuando los efectos del acto reclamado son destruidos por la autoridad de manera inmediata, absoluta e incondicional, restableciendo la situación a como se encontraba antes de la promoción del amparo, lo que impide que el quejoso obtenga la reparación constitucional en términos del artículo 80 de la propia Ley.

3. Que los efectos del acto reclamado cesaban cuando la autoridad responsable lo derogaba o revocaba, lo cual daba lugar a una situación idéntica a la que se presentaba antes del nacimiento del propio acto; o cuando la autoridad, sin revocar o dejar insubsistente el acto, constituía una situación jurídica que definitivamente destruía la que había dado motivo al amparo y reponía al quejoso en el goce de la garantía violada.

4. Que la Segunda Sala había emitido la tesis jurisprudencial número 144/2007, de rubro "AMPARO DIRECTO. ES IMPROCEDENTE POR CESACIÓN DE EFECTOS DEL ACTO RECLAMADO SI EL TRIBUNAL COLEGIADO DE CIRCUITO, AL CONOCER DE LA REVISIÓN FISCAL, REVOCA LA SENTENCIA DEL TRIBUNAL FEDERAL DE JUSTICIA FisCAL Y ADMINISTRATIVA", 5 conforme a la cual cesan los efectos del acto reclamado, actualizándose la causa de improcedencia prevista en el artículo 73, fracción XVI, de la Ley de Amparo, cuando la autoridad administrativa y el actor promueven simultáneamente la revisión fiscal y el juicio de amparo directo, respectivamente, contra la misma sentencia dictada en el juicio contencioso administrativo, y en el recurso se revoca la resolución impugnada para el efecto de que la Sala fiscal deje insubsistente su fallo y pronuncie uno nuevo, pues

3 Ibidem, febrero de 1998, t. VII, p. 210.

4 Ibidem, junio de 1999, t. IX, p. 38.

5 Ibidem, agosto de 2007, t. XXVI, p. 367. 
entonces este último ya no produce efecto ni causa agravio alguno al quejoso.

5. Que el juicio de amparo directo es improcedente por cesación de efectos del acto reclamado en términos del artículo 73, fracción XVI, de la Ley de Amparo, cuando un tribunal colegiado de circuito, en forma previa, haya resuelto otro amparo directo relacionado concediendo la protección constitucional para el efecto de que la autoridad responsable deje insubsistente dicho acto y reponga el procedimiento.

6. Que en el supuesto de que un tribunal colegiado, al resolver un amparo directo, conceda la protección constitucional para que la autoridad responsable deje insubsistente el laudo reclamado y reponga el procedimiento laboral, y se dé el caso de que al mismo tiempo conozca de otro juicio de garantías en que se impugna el mismo acto reclamado (promovido, evidentemente por la contraparte del quejoso del primer juicio), no hay duda de que, en este segundo asunto, cesan los efectos del propio acto impugnado, ya que a través de la primera sentencia protectora se destruyen los efectos del laudo de manera inmediata, absoluta e incondicional, esto es, al dejarlo insubsistente y ordenar reponer el procedimiento, el Tribunal Colegiado lo elimina de manera total y completa, lo que propicia que se restablezcan las cosas al estado en que se encontraban antes de la promoción del juicio de amparo.

7. Que ante la concesión del primer amparo analizado (relacionado con otro que se debe resolver simultáneamente), no procedía que el Tribunal Colegiado examinara los conceptos de violación expuestos en el segundo juicio de garantías, ni siquiera en el supuesto de que éstos se refirieran a violaciones procesales, incluso con independencia de su magnitud y estadio procesal en relación al motivo que originó la concesión en el primer amparo, y tampoco procedía que se declararan inatendibles los motivos de inconformidad referentes al fondo del asunto para negar el amparo solicitado, ya que existía una causa suficiente para decretar el sobreseimiento, por lo cual era inconducente estudiar la cuestión planteada en los conceptos de violación, pues por lógica elemental, cuando ante el tribunal colegiado se actualiza una razón de mayor peso, como una causal de improcedencia, excluye a todas aquellas restantes que lo llevarían a efectuar el estudio de la litis planteada, es decir, una vez ubicado el impedimento procesal 
para conocer de determinado negocio, resulta ilógico analizar los conceptos de violación para negar o conceder el amparo.

8. Que esto implicaba que la causa de improcedencia relativa a la cesación de efectos del acto reclamado se actualizaba por la concesión del amparo en el diverso expediente en que se combatió el mismo laudo, y que tenía por efecto dejarlo insubsistente, de tal suerte que al actualizarse una causa de improcedencia, el Tribunal Colegiado estaba impedido legalmente para examinar los conceptos de violación planteados en el asunto relacionado, sea cual fuere su naturaleza o trascendencia jurídica procesal, debido a que la prohibición de analizar los conceptos de violación una vez advertida una causa de improcedencia no admite excepciones, y por ello carecía de sustento ponderar si en los conceptos de violación se estaban planteando violaciones procesales o no, y de darse el primer caso, si éstas eran anteriores o posteriores a la que motivó la concesión en el primer amparo o a la importancia que dicha violación tenía en el procedimiento.

\section{CONSIDERACIONES CRÍTICAS SOBRE LA TESIS JURISPRUDENCIAL NÚMERO 225/2007}

A mi juicio, la contradicción de tesis pudo haber sido resuelta en un sentido distinto, más congruente con la garantía de administración de justicia pronta a que se refiere el artículo 17 de la Constitución federal, cuyo segundo párrafo, en lo conducente, señala que toda persona tiene derecho a que se le administre justicia por tribunales que estarán expeditos para impartirla en los plazos y términos que fijen las leyes, emitiendo sus resoluciones de manera pronta, completa e imparcial.

Lo anterior porque considero que los argumentos de la Segunda Sala están fundados en premisas que no son suficientemente concluyentes.

En efecto, es verdad que la SCJN ha sustentado el criterio de que la causal de improcedencia a que se refiere el artículo 73, fracción XVI, de la Ley de Amparo, se actualiza cuando los efectos del acto reclamado son destruidos por la autoridad de manera inmediata, absoluta e incondicional, restableciendo la situación a como se encontraba antes de la promoción del amparo, impidiendo que el quejoso obtenga la reparación constitucional en términos del artículo 80 de la propia Ley.

Ese criterio parte de la premisa de que la destrucción de los actos reclamados proviene precisamente de la autoridad responsable y no del 
Tribunal de Amparo. ${ }^{6}$ Sin embargo, el solo hecho de que se dicte la sentencia concesoria de amparo no se traduce en la eliminación inmediata del mundo jurídico del acto reclamado, pues esto más bien le corresponderá hacerlo a la autoridad responsable por tratarse del supuesto en el que se debe dictar una nueva resolución en el expediente de origen.

La existencia misma de los diversos trámites para obtener el cumplimiento de las sentencias de amparo, implica que para destruir el acto reclamado se requiere la actuación posterior de la autoridad responsable. ${ }^{7}$

Incluso, si se aceptara el criterio de que cuando se otorga la protección constitucional en uno de los dos juicios de amparo relacionados para el efecto de que se reponga el procedimiento, ya no es posible dilucidar si existió o no la violación procesal alegada en el otro juicio, con independencia de que sea anterior a aquella que se declaró existente en el primer amparo, entonces, en este supuesto no podría afirmarse que el quejoso del segundo juicio será restituido en el goce de la garantía individual que consideró transgredida en su perjuicio, pues la violación procesal que alegó no será reparada — precisamente por ser anterior a la que motivó la concesión del amparo en el primer juicio-y seguirá existiendo hasta que la autoridad responsable dicte un nuevo laudo o sentencia después de continuar con el trámite legal correspondiente.

Además, si la Segunda Sala llegó a la conclusión de que las tesis relativas a la cesación de efectos de los actos reclamados no constituían un obstáculo para dilucidar el fondo de la contradicción de tesis, entonces pudo haberla resuelto con un criterio diferente al que finalmente prevaleció, considerando las peculiaridades del propio asunto, que sí consideró

6 Tratándose de amparo directo, que es el que aquí interesa, el Tribunal Colegiado no puede intervenir en la ejecución de su fallo protector, porque el artículo 111 de la Ley de Amparo señala que esto no debe ocurrir cuando sólo las responsables puedan cumplir la ejecutoria o cuando la ejecución consista en dictar nueva resolución en el expediente o asunto que haya motivado el acto reclamado.

7 Véase al respecto, la tesis jurisprudencial número 9/2001, emitida por la Segunda Sala de la SCJN, consultable en la p. 366, t. XIV, octubre de 2001, novena época del Semanario Judicial de la Federación y su Gaceta, de rubro "CUMPLIMIENTO DE EJECUtorias de Amparo. Principios Que ha establecido la Suprema Corte de Justicia DE LA NACIÓN EN RELACIÓN CON LOS TRÁMITES, DETERMINACIONES Y MEDIOS PROCEDENTES DE DEFENSA". 
— por lo menos implícitamente- para no declarar sin materia la contradicción. ${ }^{8}$

Esto es, si la Segunda Sala hubiera determinado que el problema ya estaba resuelto por esas tesis anteriores, y que no existía alguna característica que lo distinguiera de los criterios que invocó, simplemente pudo declarar sin materia la contradicción con el contundente argumento de que ya se había establecido un criterio que la resolvía.

Respecto a la cuarta consideración de la Segunda Sala, estimo que la tesis jurisprudencial 2a./J. 144/2007, no debió ser aplicada para resolver el asunto, porque en ella no se analizó la peculiaridad que se actualizó en el caso de la contradicción 128/2007 y que permitió la resolución del fondo de esta última, es decir, que la concesión del primer amparo fue para que se dejara insubsistente el acto reclamado y se repusiera el procedimiento.

El contenido íntegro de la tesis jurisprudencial 144/2007, cuyos datos de identificación se precisaron con antelación, es el siguiente:

AMPARO DIRECTO. ES IMPROCEDENTE POR CESACIÓN DE EFECTOS DEL ACTO REClamado Si El Tribunal Colegiado DE CiRCUito, Al CONOCER DE LA REVISIÓN FISCAL, REVOCA LA SENTENCIA DEL TRIBUNAL FEDERAL DE JUSTICIA FisCAL Y ADMINISTRATIVA. Los artículos 248 del Código Fiscal de la Federación (vigente hasta el 31 de diciembre de 2005) y 63 de la Ley Federal de Procedimiento Contencioso Administrativo en vigor, establecen que las resoluciones del Tribunal Federal de Justicia Fiscal y Administrativa que decreten o nieguen el sobreseimiento y las sentencias definitivas podrán impugnarse por la autoridad a través de la unidad administrativa encargada de su defensa jurídica, interponiendo el recurso de revisión ante el Tribunal Colegiado de Circuito competente en la sede del Pleno, sección o sala regional a que corresponda. Ahora bien, si la autoridad administrativa y el actor promueven simultáneamente la revisión fiscal y el juicio de amparo directo, respectivamente, contra la misma sentencia, y en aquélla se revoca la resolución impugnada para el efecto de que la responsable deje insubsistente el acto reclamado y pro-

8 Véase tesis jurisprudencial núm. 32/2004, emitida por la Primera Sala de la Suprema Corte de Justicia de la Nación, publicada en la p. 293, t. XIX, de mayo de 2004, Novena Época, del Semanario Judicial de la Federación y su Gaceta, con el rubro "CoNTRADICCIÓN DE TESIS. SI LA JURISPRUDENCIA QUE RESOLVIÓ EL PUNTO CONTRADICTORIO DENUNCIADO, SE EMITIÓ ANTES DE LA PRESENTACIÓN DEL ESCRITO DE DENUNCIA, DEBE DECLARARSE IMPROCEDENTE Y NO SIN MATERIA", en la que se establecen los criterios para declarar sin materia o improcedente una contradicción de tesis. 
nuncie uno nuevo en el que siga los lineamientos de la ejecutoria, es evidente que cesan los efectos del acto reclamado en el juicio de garantías y se actualiza la causal de improcedencia prevista en el artículo 73, fracción XVI, de la Ley de Amparo, en virtud de que la sentencia recurrida ya no produce efecto alguno ni causa agravio al quejoso.

Incluso, el criterio al que se refiere dicha tesis no debió ser aplicado por analogía, porque la revisión fiscal es un recurso de legalidad, en el que el Tribunal Colegiado que conoce de la misma, revoca, modifica o confirma, por sí, la sentencia impugnada dictada por el Tribunal Administrativo, mientras que en el amparo no ocurre esto último, sino que, como lo señalé, para restituir al quejoso en el goce de la garantía individual violada, se requiere tramitar un procedimiento específico para lograr que sea la autoridad responsable quien cumpla con lo ordenado en el fallo protector.

En el mismo orden de ideas, en cuanto a la sexta consideración de la Segunda Sala, estimo que la concesión del amparo en la primera sentencia de garantías, no destruye los efectos del laudo o sentencia reclamada de manera inmediata, absoluta e incondicional, sino que esto, como lo precisé, le corresponde hacerlo a la autoridad responsable, quien debe restablecer las cosas al estado en que se encontraban antes de la promoción del juicio de amparo.

Por lo demás, respecto al octavo razonamiento de la Segunda Sala, considero que nada impide legalmente que el Tribunal Colegiado examine los conceptos de violación planteados en el segundo juicio de garantías, referidos a cuestiones de carácter procesal, ni que declarare inatendibles los motivos de inconformidad relacionados con el fondo del asunto y que, como consecuencia de ello, niegue el amparo solicitado.

En efecto, si el artículo 65 de la Ley de Amparo establece que los juicios de amparo directo se relacionen para resolverlos simultáneamente, es con el objeto de que el problema planteado se decida de la manera más completa y objetiva posible, tomando en cuenta la totalidad de los argumentos expresados contra un solo acto por personas que generalmente acuden al juicio de origen y al amparo con intereses opuestos, y esa resolución se entiende que se emite en el mismo momento de la sesión, de tal suerte que esto implica que cuando se dicta el fallo constitucional en ambos juicios, el acto reclamado aún subsiste.

El artículo 65, primer párrafo, de la Ley de Amparo, dice: 
Artículo 65. No son acumulables los juicios de amparo que se tramiten ante un tribunal colegiado de circuito o ante la Suprema Corte de Justicia, ya sea en revisión o como amparos directos; pero cuando alguna de las salas o el tribunal mencionado encuentren que un amparo que hayan de resolver tiene con otro o con otros de la jurisdicción de la propia sala o del mismo tribunal, una conexión tal que haga necesario o conveniente que todos ellos se vean simultáneamente, a moción de alguno de los ministros que la integran o de alguno de los magistrados del tribunal colegiado de circuito respectivo, podrán ordenarlo, así, pudiendo acordar también que sea un ministro o magistrado, según se trate, quien dé cuenta con ellos...

De igual forma, considero que se pudo haber armonizado perfectamente esa posibilidad de resolver los juicios simultáneamente con la garantía de pronta administración de justicia, estableciendo que, con las excepciones a las que luego me referiré, en ambos juicios se deben analizar las violaciones procesales propuestas por cada quejoso, con independencia de que sólo alguna de ellas pueda conducir al otorgamiento de la protección constitucional.

Además, en esas hipótesis la cuestión de la improcedencia del segundo juicio se podía haber salvado con el argumento de que la autoridad responsable aún no deja insubsistente la resolución reclamada, y que, en todo caso, si también se expresan conceptos de violación con relación a aspectos de fondo, éstos no pueden ser examinados por virtud de la reposición del procedimiento, lo cual dejaría a salvo el derecho de la parte quejosa para hacer valer esas mismas cuestiones en un amparo posterior.

Aunado a lo anterior, estimo que, como lo señaló la Segunda Sala, es verdad que la causal de improcedencia a que se refiere el artículo 73, fracción XVI, de la Ley de Amparo, no establece excepciones expresas; sin embargo, esto no constituía obstáculo para que se examinaran otros preceptos de la citada Ley (como el 65), incluso, el artículo 17 constitucional, para llegar a la conclusión de que se estaba en presencia de un caso específico que ameritaba una solución más congruente con la economía procesal y la garantía de pronta administración de justicia, sobre todo porque, como lo precisé, la sentencia o laudo reclamado no queda insubsistente con el solo dictado del fallo constitucional, sino que requiere una actuación precisa de la responsable de acuerdo con lo ordenado en capítulo XX, título primero, libro primero, de la citada Ley. 
Como también lo mencioné, el criterio que aquí sostengo lo expreso con algunas reservas, pues considero que cuando la violación procesal alegada en uno de los juicios de amparo es posterior a la aducida en el juicio relacionado, y su existencia está íntimamente vinculada con aquélla (e. g., cuando uno de los quejosos impugna la admisión de una prueba y el otro su incorrecto desahogo, o cuando uno de ellos controvierte la falta de prevención para aclarar la demanda y el otro se refiere a una cuestión probatoria), entonces, considero que debe prevalecer el criterio de que el segundo juicio, relativo a la violación más reciente cuyos efectos dependen de lo que se resuelva sobre la primera, debe ser sobreseído invocando precisamente la causal de improcedencia prevista en el artículo 73, fracción XVI, de la ley de la materia, pero no por las razones que expresó la Segunda Sala, sino por una cuestión de prelación lógica y de orden procesal.

En todo caso, estimo que la determinación de si se actualiza o no la causal de improcedencia aludida, se debió dejar al razonable criterio del Tribunal Colegiado de Circuito que corresponda, determinando que el examen de cada situación permitiría establecer si procedía o no analizar los conceptos de violación en el segundo juicio de amparo y cuál de los dos debe ser examinado primero.

Concretamente, las situaciones que pueden presentarse en esos casos pueden reducirse a cinco, que son las que enseguida menciono, en la inteligencia de que sólo para evitar confusiones, denominaré primer juicio o primer amparo a aquel en el que se concede la protección constitucional para que se reponga el procedimiento, y segundo juicio o segundo amparo al que, según el criterio de la Segunda Sala, debe ser sobreseído:

a) que luego de examinar las violaciones procesales que se invoquen en el segundo juicio, se determine que no existieron, con independencia del momento en que la parte quejosa afirme que se hayan producido;

b) que la violación procesal alegada en el segundo juicio sea anterior o simultánea a la del primero que motivó la concesión del amparo, y no tenga relación ni pueda incidir en esta última;

c) que la violación procesal aducida en el segundo juicio efectivamente haya existido, sea posterior a la advertida en el primer juicio, pero su resolución dependa de la forma como se subsane esta última (e.g., el caso al que se aludió con antelación, cuando una parte impugna la admisión de una prueba y la otra, que la ofreció, su incorrecto desahogo); 
d) que la violación procesal que se haga valer en el segundo juicio se haya producido en un momento posterior al de aquélla que se reclamó en el primer juicio y que no dependa ni se vea afectada por la forma como se vaya a subsanar esta última; y

e) que la violación procesal aducida en el segundo juicio sea anterior a la del primer juicio y tenga relación directa o pueda incidir en aquélla por la que se propuso conceder el amparo en el primer juicio. ${ }^{9}$

El examen de esas cinco posibilidades, permitiría determinar si en el amparo relacionado con otro en el que, en la misma sesión, se propone otorgar la protección constitucional para efectos de reposición del procedimiento, es posible o no examinar los conceptos de violación en los que también se alegue la existencia de violaciones de carácter procesal.

De acuerdo con esa perspectiva, podrían establecerse las siguientes reglas, correlativas a los casos aludidos:

1. En el primer supuesto nada impediría analizar los conceptos de violación planteados en el segundo amparo relativos a la cuestión procesal cuya existencia no se acredita y, en consecuencia, declararlos infundados (por la inexistencia de la violación procesal), y si también se hubieran expresado argumentos en cuanto al fondo, se debería determinar que no es el caso de examinarlos en razón de la reposición del procedimiento ordenada en el primer amparo, dejando al quejoso en aptitud de plantearlos cuando se llegue a dictar el nuevo laudo o sentencia que corresponda, en el supuesto de que resulte contrario a sus intereses.

2. Si existiera la violación procesal alegada en el segundo juicio, y fuera anterior o simultánea a la que se advirtió en el primero y no tuviera relación ni incidiera en esta última, entonces habría que analizarla y conceder el amparo para que se subsanara, es decir, en ambos amparos se concedería el amparo para efectos de que se repusiera el procedimiento y se subsanaran las violaciones procesales. En la inteligencia de que, como ocurre siempre en estos casos, si también se hubieran alegado violaciones de fondo en ese segundo juicio (o en el primero, obviamente), se omitiera el estudio de las mismas y se

9 Como se ve, algunos de estos supuestos parecen prefigurarse del segundo razonamiento de los que sostuvo el Segundo Tribunal Colegiado del Décimo Primer Circuito, y que la Segunda Sala consideró que no constituía el argumento toral del sentido de su resolución. 
dejara a los quejosos en aptitud de hacerlas valer nuevamente cuando se llegara a dictar el laudo o resolución correspondiente en el caso de que, en todo o en parte, resultara desfavorable a sus intereses;

3. En la tercera hipótesis, es decir, si la violación procesal aducida en el segundo juicio efectivamente hubiera existido, pero fuera posterior a la advertida en el primer juicio y su resolución estuviera íntimamente relacionada y tuviera incidencia sobre esta última, entonces, lo correcto sería declarar la improcedencia del segundo amparo, por la imposibilidad de examinar tanto la violación alegada como las cuestiones de fondo;

4. Cuando se advirtiera que sí existieron las violaciones procesales aducidas en el segundo amparo, y que se cometieron con posterioridad a la que motivó que se ordenara la reposición del procedimiento en el primer juicio, sin que exista vinculación entre ellas, entonces también procedería conceder el amparo en el segundo juicio, con el objeto de que todas las cuestiones procesales quedaran subsanadas; en el entendido de que si en ese segundo juicio también se estuvieran alegando violaciones de fondo, se debería determinar que sólo sería posible examinarlas hasta que se dictara en su momento el laudo o resolución correspondiente, $\mathrm{y}$

5. Si existió la violación procesal alegada en el segundo juicio, fue anterior a la que motivó la propuesta de conceder el amparo en el primer juicio y podría incidir en esta última, entonces lo más correcto sería conceder la protección constitucional en ese segundo amparo (aplicando el tercer criterio), y decretar el sobreseimiento del primero.

Esas formas de resolver sólo podrían ser adoptadas en el momento mismo de la sesión del Tribunal correspondiente, cuando simultáneamente se resuelven los amparos relacionados, en términos del artículo 65 de la ley de la materia, sopesando en cada caso las razones que justificarían analizar o no las violaciones procesales, según correspondiera.

Este criterio, como lo he venido señalando, encuentra apoyo en la garantía de pronta administración de justicia, mientras que lo determinado por la Segunda Sala se traduce en la posibilidad de que se deban promover varios juicios sucesivos para agotar el estudio de las violaciones procesales, siendo que en algunos supuestos esos aspectos pueden - $-\mathrm{y}$ debenquedar resueltos en una sola oportunidad. 
Este criterio no es totalmente novedoso, pues algo de su sentido se podría inferir del Proyecto de Nueva Ley de Amparo elaborado por la Suprema Corte de Justicia de la Nación, en cuyo artículo 172 se proponía la exigencia de que en el amparo directo se plantearan todas las violaciones de carácter procesal y se analizaran todas ellas bajo la sanción de que las violaciones no aducidas o no advertidas en suplencia de la queja en un primer amparo, se tendrían por consentidas y ya no podrían ser examinadas en un posterior juicio de garantías. Incluso, en el mismo proyecto se hablaba de establecer el amparo adhesivo, precisamente para que todas las violaciones procesales se analizaran en una sola oportunidad.

Esto se apreciará con mayor claridad observando el texto del artículo indicado, que dice:

Artículo 172. En la demanda de amparo el quejoso deberá hacer valer todas las violaciones procesales que estime se cometieron; las que no se hagan valer se tendrán por consentidas. Asimismo, precisará la forma en que trascendieron en su perjuicio al resultado del fallo.

El Tribunal Colegiado de Circuito de Amparo, deberá decidir respecto de todas las violaciones procesales que se hicieron valer y aquellas que, en su caso, advierta en suplencia de la queja.

Si las violaciones procesales no se invocaron en un primer amparo, ni el Tribunal Colegiado correspondiente las hizo valer de oficio en los casos en que procesa la suplencia de la queja, no podrán ser materia de concepto de violación ni de estudio oficioso en juicio de amparo posterior. ${ }^{10}$

La finalidad de esa propuesta consistía precisamente en evitar la proliferación de amparos, que es una de las quejas más comunes del foro, como lo resaltó en su momento Arturo Zaldívar Lelo de Larrea, quien con relación a ello, señala:

El funcionamiento actual del amparo directo es fuente de inútil alargamiento de los procedimientos ordinarios que le dan origen. La técnica con la que opera este tipo de amparo genera que, dentro de un mismo procedimiento, se dé lugar a un número importante de juicios de amparo en contra de la sentencia definitiva, sin que a través del amparo se resuelva el fondo del asunto

10 Suprema Corte de Justicia de la Nación, Proyecto de la Suprema Corte de Justicia de la Nación de la Ley Reglamentaria de los Artículos 103 y 107 de la Constitución Política de los Estados Unidos Mexicanos, México, SCJN, 2001, p. 194. 
sino después de varios años de litigio adicional al que requirió el juicio de origen.

Este es un añejo problema, que se refleja en los llamados: amparos para efectos. Se trata de aquellos juicios de amparo en que después de varios años de litigarse en primera y segunda instancia, llegan a un tribunal colegiado, dicho colegiado analiza una violación procesal, la considera fundada y regresa el expediente a la responsable; se repone la violación procesal, después de seis meses regresa a la justicia federal en un nuevo amparo; se tarda seis meses en resolver el colegiado, y hay otra violación procesal; así pasamos todas las violaciones procesales, pero después vienen las violaciones in judicando, y así pueden transcurrir, cinco, siete, ocho, o nueve años en lo que en el foro ya se llama el amparo ping pong.

Esta situación patológica provoca mucho del rezago que tienen los tribunales federales, si se toma en cuenta que un solo juicio emanado de la justicia ordinaria puede requerir un número variable de juicios de amparo. Asimismo, evita que la justicia sea pronta y expedita y, por tanto, en muchos casos no sea justa. ${ }^{11}$

Como se ve, el problema examinado en este breve ensayo tiene indudable vinculación con esa situación patológica a la que se refiere el mencionado autor. Por esa razón, de acuerdo con lo anteriormente expuesto, estimo que al resolver la contradicción de tesis 128/2007, la Segunda Sala de la Suprema Corte de Justicia de la Nación, pudo haber emitido un criterio más congruente con la tendencia a disminuir el número de juicios de amparo, aplicando e interpretando en forma armónica las disposiciones legales y constitucionales en vigor.

Finalmente, considero pertinente preguntar si el mismo criterio sustentado por la Segunda Sala en la tesis jurisprudencial 225/2007, podría llegar a ser aplicado en el caso de que se presentara una contradicción de tesis que examinara el problema de los amparos relacionados en los que sólo se aducen cuestiones de fondo y en uno de ellos se concede la protección constitucional.

Empleando en sentido estricto las razones contenidas en dicha tesis jurisprudencial, estimó desafortunadamente que la respuesta debería ser afirmativa, porque la Segunda Sala señaló que una vez otorgada la protección constitucional en uno de los amparos relacionados, el acto reclamado

11 Zaldívar Lelo de Larrea, Arturo, Hacia una nueva Ley de Amparo, México, UNAM, Instituto de Investigaciones Jurídicas, 2002, p. 129. 
queda insubsistente en forma inmediata, por lo cual el otro juicio debe ser sobreseído, sin mayor estudio.

En esa tónica, la misma razón podría ser aplicada a los juicios relacionados en los que únicamente se hagan valer cuestiones de fondo, lo que también redundaría en un mayor retardo en la administración de justicia, por la proliferación de los juicios de garantías contra actos derivados de un mismo procedimiento, aun cuando se refirieran a temas de fondo desvinculados (e.g., cuando en un amparo directo se reclama la condena o absolución por concepto de horas extras y en el juicio relacionado la condena o absolución por concepto de prima de antigüedad, etcétera).

Sin embargo, como la tesis jurisprudencial 225/2007, no analizó ese problema específico, estimo que no sería conveniente ni obligatorio que la aplicaran analógicamente los tribunales colegiados de circuito.

\section{CONCLUSIÓN}

Considero que las razones expuestas a lo largo de este breve ensayo conducen a concluir que la Segunda Sala de la Suprema Corte de Justicia de la Nación, pudo haber resuelto en forma distinta la contradicción de tesis $128 / 2007$, considerando las peculiaridades del caso y estableciendo un criterio más flexible que respetara la garantía de pronta administración de justicia a que se refiere el artículo 17 constitucional.

Esencialmente, se debió establecer la posibilidad de analizar los conceptos de violación referentes a aspectos procesales planteados en un amparo directo relacionado con otro en el que, en la misma sesión, se propone conceder la protección constitucional para el efecto de que se reponga el procedimiento, considerando para ello el momento en que se cometió la violación alegada en cada juicio y la vinculación o la incidencia entre una y otra, de acuerdo con los criterios apuntados con antelación, lo cual daría lugar a que se colmara el estudio de las cuestiones de carácter procedimental para evitar la promoción de amparos posteriores en cuanto a los aspectos de esa índole. 